\title{
MULTILETRAMENTOS E ENSINO DE LÍNGUA PORTUGUESA NA CONTEMPORANEIDADE
}

\author{
Luana Gomes Pereira \\ Bacharel e licenciada em Letras Português/Inglês pela UFRJ. Mestre e doutora em Linguística pela UFRJ. \\ Mediadora pedagógica presencial do CEDERJ. \\ https://orcid.org/0000-0002-1709-781X
}

Data de submissão: 01/05/2021

Data de aprovação: 23/06/2021

\section{RESUMO}

A vivência em um mundo multicultural, com a integração de diversas semioses, leva-nos a repensar o ensino de língua na escola e as inevitáveis mudanças emergentes para adequálo às necessidades atuais. Neste sentido, este trabalho busca apresentar considerações sobre os desdobramentos dos multiletramentos com o uso das Tecnologias Digitais de Informação e Comunicação (TDIC) e sua relação com o ensino de língua portuguesa na Educação Básica. Faremos uma exposição de levantamento bibliográfico, tendo em vista a utilização dos gêneros textuais discursivos contemporâneos prevista na BNCC (Base Nacional Comum Curricular) e a abordagem de ensino de multiletramentos, buscando refletir sobre como as novas tecnologias podem influenciar nossa prática institucional de ensinar e aprender no século XXI. Com esta análise, concluímos que é necessária uma postura reflexiva do educador que atua como um facilitador da aprendizagem significativa, tornando o aluno um sujeito ativo na construção do conhecimento da língua ao demonstrar domínio na produção e utilização dessas linguagens.

Palavras-chave: multiletramentos; gêneros textuais; ensino; BNCC; língua portuguesa.

\section{MULTILITERACIES AND PORTUGUESE LANGUAGE TEACHING IN CONTEMPORANEITY}

\section{ABSTRACT}

Living in a multicultural world, with the integration of several semiosis, leads us to rethink language teaching at school and the inevitable emerging changes due to adapt it to current needs. In this sense, this work aims to present considerations on the consequences of the multiliteracies with the use of Digital Information and Communication Technologies (TDIC) and their relationship with the teaching of Portuguese in Basic Education. We will make a bibliographic survey presentation, in view of the use of contemporary discourse genres provided for in the BNCC (National Common Curricular Base) and the multiliteracies teaching approach, aiming to reflect on how new technologies can influence our institutional practice of teaching and learning in the 21st century. With this analysis, we conclude that it is necessary a reflective posture of the educator who acts as a facilitator of meaningful learning, making the student an active subject in the construction of knowledge of the language by demonstrating mastery in the production and use of these languages. 
Keywords: multiliteracies; textual genres; teaching; BNCC; portuguese language.

\section{MULTILITERACIDAD Y ENSEÑANZA DE LENGUA PORTUGUESA EN LA CONTEMPORANEIDAD}

\section{RESUMEN}

Vivir en un mundo multicultural, con la integración de varias semiosis, nos lleva a repensar la enseñanza de idiomas en la escuela y los inevitables cambios que van surgiendo para adaptarla a las necesidades actuales. En este sentido, este trabajo busca presentar consideraciones sobre las consecuencias de las multiliteracidades con el uso de las Tecnologías de la Información y la Comunicación Digitales (TDIC) y su relación con la enseñanza del portugués en la Educación Básica. Realizaremos una exposición de estudio bibliográfico, teniendo en cuenta el uso de los géneros discursivos contemporáneos previstos en la BNCC (Base Nacional Común Curricular) y el enfoque docente de las multiliteracidades, buscando reflexionar sobre cómo las nuevas tecnologías pueden influir en nuestra práctica institucional de enseñanza y aprendizaje en el siglo XXI. Con este análisis, concluimos que es necesaria una postura reflexiva del educador que actúe como facilitador de aprendizajes significativos, para que el alumno sea un sujeto activo en la construcción del conocimiento del lenguaje al demostrar dominio en la producción y uso de estos lenguajes.

Palabras clave: multiliteracidad; géneros textuales; enseñanza; BNCC; lengua portuguesa.

\section{INTRODUÇÃO}

Percebe-se no ensino-aprendizado de Língua Portuguesa o surgimento de um novo paradigma voltado ao letramento integral. Neste artigo trazemos uma discussão sobre o emprego da perspectiva de multiletramentos no ensino de Língua Portuguesa, a fim de contribuir com o letramento integral, considerando o mundo multimodal e as orientações da Base Nacional Curricular Comum (doravante BNCC). Com o crescimento da cultura digital, o ensino de novos letramentos e de uma postura de criticidade para as novas linguagens se colocam como desafios para a escola. Consideramos pertinente e necessário trazer essas formas de comunicação e informação para dentro da escola, para que esta seja percebida como parte da sociedade e reflita seus usos e suas escolhas. É relevante que o ensino-aprendizado da língua portuguesa inclua os diversos gêneros textuais produzidos na atualidade, através do engajamento discursivo para o desenvolvimento de uma consciência crítica sobre o próprio aprendizado.

O ser humano da contemporaneidade se insere no mundo de forma multicultural, com grande diversidade em sua população. Junto a isso, observamos a emergência de uma multiplicidade semiótica na produção textual, o que implica haver variadas formas de comunicação e informação. Com isso, encontramos hoje - especialmente em ambientes urbanos - indivíduos totalmente inseridos no contexto digital, o que nos leva a repensar as abordagens de ensino utilizadas na escola e o quanto isso reflete o mundo atual.

Dentro deste contexto, a vida se apresenta com dimensões digitais e virtuais, nas quais variados gêneros textuais são veiculados e incorporam-se gradativamente no nosso quotidiano. Uma vez que consideramos a língua como uma manifestação social que se 
insere neste mundo de configuração tão dinâmica e heterogênea, o papel do ensino tende a se transformar para que se adeque às novas demandas educacionais contemporâneas.

Considerando a conjuntura dos processos digitais e o ensino, surgem as questões: como os conceitos de leitura e produção textual se inserem na perspectiva de multiletramentos? Como o uso das tecnologias contemporâneas pode influenciar nossa prática institucional de ensinar e aprender? Uma vez que se entenda que os processos utilizados na escola devem se adaptar a essa realidade emergente, de que maneira as orientações curriculares para a atuação do professor devem inserir o reconhecimento dos novos gêneros e dos multiletramentos em sala de aula?

Desta forma, neste trabalho buscamos discutir os multiletramentos no ensino de língua portuguesa, tomando por base a perspectiva de estudos de gêneros textuais adotada na BNCC. A BNCC é um documento normativo que promove orientações sobre as práticas de leitura e produção de textos multimodais, dentre eles os que encontramos em espaços digitais.

Esta análise se justifica por considerarmos as novas tecnologias como parte de diversas formas de construção de conhecimento na educação atual. Com isso, os multiletramentos inseridos na esfera digital promovem outro olhar sobre as maneiras de aprender e ensinar, necessário para a formação de alunos que se situem e compreendam a complexidade social dos tempos atuais.

\title{
2 REFERENCIAL TEÓRICO
}

Nesta seção, discutimos um pouco sobre o arcabouço teórico utilizado para embasar nossas perspectivas e análises, partindo da pedagogia de multiletramentos defendida por Rojo (2004) e Rojo e Moura (2012), a qual advoga por uma leitura crítica e plural das práticas de produção de texto. Apresentamos também considerações sobre as propostas da BNCC para o ensino de leitura e produção textual através de textos multimodais.

\subsection{A leitura $e o$ ato de ler}

A leitura, vista sob uma ótica tradicional, é um processo estritamente ligado à escrita, e se configura como parte do desenvolvimento linguístico de cada indivíduo. Nas palavras de Anecleto e Oliveira (2019, p.243):

\begin{abstract}
A leitura apresenta-se como um meio importante na formação do sujeito enquanto ser crítico dentro da sociedade, pois essa habilidade possibilita que os alunos se legitimem na cultura escolar e em espaços sociais. Dessa forma, a escola deve ser promotora de práticas letradas, ampliando o uso da diversidade de tipos e gêneros textuais e discursivos em sala de aula para promover maior e melhor formação de competências comunicativas.
\end{abstract}

Sendo assim, podemos caracterizar o processo de letramento como a inter-relação entre práticas de leitura e escrita que, hoje em dia, manifestam-se de forma plural - o que nos leva ao conceito de multiletramentos.

\subsubsection{Multiletramentos}

Conforme começamos a discutir na seção anterior, o letramento se configura em um conjunto de práticas tanto individuais quanto sociais, uma vez que a leitura de um mesmo texto pode levar os seus leitores a diferentes interpretações de seu conteúdo, considerando o contexto cultural em que está inserido, seu conhecimento de mundo, ou até mesmo o tipo de suporte em que ele se materializa. 
Partindo das considerações iniciais de Kleiman, (1995, p.20) definimos o letramento "um conjunto de práticas sociais que usam a escrita, enquanto sistema simbólico e enquanto tecnologia, em contextos específicos, para objetivos específicos". No entanto, o uso dos textos nas Tecnologias Digitais de Informação e Comunicação (TDIC) vai além das considerações que versam apenas sobre a escrita: temos uma produção híbrida - com textos, sons, imagens e movimento - e uma atuação mais colaborativa dos interlocutores.

Desta forma, não pensamos mais em letramentos, mas sim em "multiletramentos", pois se tornou necessário um novo entendimento das práticas discursivas de linguagem em um mundo com tanta diversidade cultural e digital. Esta noção, defendida por estudiosos da língua reunidos em 1996, resultou em um manifesto pela "pedagogia de multiletramentos". Para Rojo (2004), um dos maiores expoentes brasileiros que advoga por esta concepção, existem diversas maneiras de se ler e escrever. Em um documento sobre orientações para o ensino, a autora afirma que "[...] 'multiletramento', aqui, significa que compreender e produzir textos não se restringe ao trato do verbal oral e escrito, mas à capacidade de colocar-se em relação às diversas modalidades de linguagens" (ROJO, 2004, p.31).

Com isso em vista, a multiplicidade cultural, vinculada à multiplicidade semiótica aqui exposta (ROJO; MOURA, 2012), faz com que novas concepções de leitura e produção textual sejam criadas a partir de um letramento anterior, baseado nas produções de fala e escrita que já conhecíamos antes da era digital. Como consequência, temos que considerar os textos multimodais para repensar a educação. Muitas vezes, as propostas de ensino e aprendizagem podem estar estanques em um modelo ultrapassado, que não considera as transformações sociais vividas nos últimos anos. Isso torna a escola um espaço distante da realidade, e incapaz de promover práticas que promovam o pensamento crítico dos alunos em relação aos textos, à linguagem e às relações sociais.

Para uma aproximação do ensino de língua portuguesa com a real produção de textos no mundo, cabe incentivar uma abordagem que englobe diversos gêneros textuais discursivos que estão presentes no quotidiano do alunado. Na próxima seção, trataremos da definição de gêneros textuais discursivos, a fim de fundamentar sua utilização em sala de aula.

\subsection{Os gêneros textuais discursivos}

Vários autores já apresentaram definições sobre o que são gêneros textuais discursivos, dentre eles Swales (1990) e, em português, Meurer (2002) - em sua coletânea de textos sobre o fenômeno. Em uma perspectiva dialógica, podemos considerar os gêneros textuais como manifestações da linguagem que ocorrem de maneira maleável, a fim de suprir necessidades comunicativas em atividades socioculturais de cada sociedade, inseridos em um momento histórico e influenciados pelas inovações da tecnologia.

Nas palavras de Bakhtin (1992, p.37):

Todas as esferas da atividade humana, por mais variadas que sejam, estão relacionadas com a utilização da língua. Não é de se surpreender que o caráter e os modos dessa utilização sejam tão variados como as próprias esferas da atividade humana [...]. O enunciado reflete as condições específicas e as finalidades de uma dessas esferas, não só por seu conteúdo temático e por seu estilo verbal, pela seleção operada nos recursos da língua - recursos lexicais, fraseológicos e gramaticais - mas também, e sobretudo, por sua construção composicional.

Todos os gêneros textuais emergem em um contínuo fala-escrita (MARCUSCHI, 2002), variando dentro de cada modalidade em sua forma de registro mais ou menos formal, de acordo com suas funções comunicativas. Resumidamente, os gêneros textuais 
exprimem formas de agir socialmente através do uso da língua, e servem para nos orientar quanto às expectativas de produção textual.

Como meio de materialização da comunicação humana, os gêneros textuais são criados a partir de novas demandas sociais, e as TDIC exercem forte influência para a configuração de novos gêneros. Para Marcuschi (op.cit), a intensidade de uso das novas tecnologias propicia a criação de novos gêneros, com formas inovadoras, porém surgidas de velhas bases que são redefinidas de acordo com as necessidades dos falantes. São exemplos de novos gêneros digitais o meme, o post, o GIF, o tweet, dentre outros.

Entretanto, em muitos manuais de ensino de língua, vemos que os gêneros textuais abordados ainda são sempre os mesmos, apesar do número ilimitado de possibilidades. É bem verdade que os professores se queixam por haver uma dificuldade em se trabalhar gêneros textuais na escola de forma sistemática, porém há um movimento para que realize o ensino de língua a partir de textos autênticos.

Na subseção a seguir, abordaremos como o ensino de diferentes gêneros textuais vem sendo ampliado e promovido pelos documentos oficiais que orientam a Educação Básica.

\subsubsection{O ensino dos gêneros textuais e a BNCC}

Com a redução dos textos escritos impressos e o aumento da democratização de acesso aos meios digitais - considerando uma população urbanizada - podemos perceber alguns reflexos do uso de tecnologias digitais em nosso cotidiano, o que inclui o contexto da educação.

A partir do uso mais amplo dos suportes virtuais, a leitura passa a apresentar novas estruturas, significados e ações, promovendo mudanças nos modos de ler, analisar e entender um texto. O leitor passa a interagir com o autor e com o texto, o qual apresenta diversas possibilidades de configuração visual - com hiperlinks e representações de som e imagem. Em muitos casos, o leitor também é cocriador de conteúdo, o que permite considerá-lo como um interlocutor colaborativo.

O Ministério da Educação, ao tentar promover orientações para as instituições de ensino, fornece documentos orientadores e/ou regulatórios para a elaboração dos currículos escolares. Atualmente, temos a Base Nacional Curricular Comum (BNCC), que orienta o conjunto de aprendizagens a serem trabalhadas na Educação Básica. Este documento foi desenvolvido com a participação de vários educadores, a fim de nortear as ações dos Estados e Municípios na construção dos currículos da Educação Básica.

A BNCC é um documento normativo, que está em conformidade com o Plano Nacional de Educação, e que preconiza aquilo que os alunos devem aprender em sua formação na Educação Básica, conforme descrito em seu texto:

(...) de caráter normativo que define o conjunto orgânico e progressivo de aprendizagens essenciais que todos os alunos devem desenvolver ao longo das etapas e modalidades da Educação Básica, de modo a que tenham assegurados seus direitos de aprendizagem e desenvolvimento, em conformidade com o que preceitua o Plano Nacional de Educação (PNE). (BRASIL, 2018, p. 7)

Conforme destacado por Mendes Gontijo (2015, p.181), ainda sobre o primeiro texto do documento, mas que se mantém em sua terceira versão, de 2018, a Base "não somente apresenta subsídios para orientar os currículos nos estados, municípios e escolas, mas pretende protagonizar mudanças para melhora na educação nacional". Assim, baseia-se no desenvolvimento de competências e diretrizes que são comuns a todas as escolas, 
porém com possibilidades de aplicação de currículos diferentes em cada contexto educacional. Sendo assim, não é um documento fechado em si, mas com a possibilidade de diferentes aplicações a depender das demandas educacionais de cada região.

Verificamos que a BNCC se organiza em torno de cinco áreas de conhecimento: Linguagens, Matemática, Ciências Humanas, Ciências da Natureza e Ensino Religioso. A Língua Portuguesa é considerada um dos componentes curriculares da área de Linguagem, que engloba também os componentes Artes, Educação Física e Inglês. O componente de Língua Portuguesa abrange quatro eixos: leitura/escuta; produção (escrita e multissemiótica); oralidade; análise linguística/semiótica.

$\mathrm{Na}$ construção da área de Linguagens e dentro do componente de Língua Portuguesa, podemos observar a centralidade do texto como forma de trabalho para além da análise linguística, o que já vinha sendo discutido em outros documentos oficiais da área de educação. Os conhecimentos sobre os gêneros textuais e o uso da língua são construídos com o objetivo de desenvolver as capacidades de leitura, produção e tratamento das diferentes linguagens (e suas semioses), que permitem a participação em práticas de diferentes campos da atividade humana.

De qualquer forma, de modo geral, a BNCC trata de textos multimodais e multiculturais, cada vez mais frequentes em nosso quotidiano, estendendo a visão semiótica para a análise textual. $\mathrm{Na}$ seção seguinte, descreveremos nossa escolha metodológica para este trabalho e, em seguida, partiremos para a discussão e análise sobre o ensino de Língua Portuguesa a partir dos textos multimodais e das propostas da BNCC.

\section{METODOLOGIA}

A metodologia utilizada nesta pesquisa é qualitativa e considerou como estratégia a elaboração de uma pesquisa exploratória bibliográfica. Nossa proposta foi discutir conceitos sobre o ensino de leitura e produção textual em uma perspectiva de multiletramentos, considerando as disposições sugeridas pela BNCC.

Para isso, utilizamo-nos da perspectiva de Pedagogia de multiletramentos defendida por Rojo (2004) e da proposta curricular definida pelo Ministério da Educação na Base Nacional Comum Curricular (BNCC), obrigatória desde 2019. Tais textos foram selecionados como referência devido a sua importância na definição do conceito de multiletramentos e sua orientação para a atividade escolar, bem como pelo caráter normativo que norteia esta atuação.

A partir da consideração da literatura sobre multiletramentos e do texto apresentado no documento oficial, investigamos e analisamos criticamente como o conceito foi introduzido para a criação das propostas curriculares de ensino-aprendizagem de Língua Portuguesa na Educação Básica no Brasil.

\section{ANÁLISE E DISCUSSÃO DOS RESULTADOS}

Nesta seção, discutiremos a relação do ensino-aprendizagem de Língua Portuguesa com os multiletramentos, em busca de uma pedagogia dialógica, considerando a proposta de ensino da BNCC. Teceremos algumas considerações sobre esta perspectiva e como esta pode ser implementada de acordo com as proposições do documento oficial.

\subsection{0 ensino de língua portuguesa através dos multiletramentos}


O ensino de Língua Portuguesa sempre foi muito centrado sobre a modalidade escrita. No entanto, a docência de língua e linguagem nos novos tempos precisou se reestruturar para continuar a fazer sentido na sociedade. O professor precisa estar a pa

$r$ das mudanças sociais e culturais apresentadas pela inserção das novas tecnologias em nosso cotidiano e saber utilizá-las em favor do ensino para a construção de aprendizagem significativa por parte de seus alunos.

Nas considerações filosóficas de Lévy (1999), em uma época em que se usava o termo "cibercultura" para designar a cultura produzida via tecnologias digitais, tal efeito provoca uma mudança da relação que criamos com o saber. Tais relações aumentam, exteriorizam e alteram diversas funções cognitivas que possuímos, transformando até mesmo nosso entendimento do que é memória. Na cultura do texto eletrônico, percebemos que o letramento digital traz uma nova forma de ler, pois os leitores de hipertextos podem interferir na sua produção, acrescentando, alterando, mostrando seus próprios caminhos de leitura.

Silva e Trotta (2019, p.46) também apresentam considerações quanto ao uso de hipertextos - neste artigo, especificamente no contexto da EJA - sobre o qual concluem:

O hipertexto é uma ferramenta livre, que pode ser usada a partir de mídias sociais, como Facebook e Whatsapp, além de blogs e e-mails. É um ambiente digital muito conhecido em várias instâncias da educação, mas pode ser muito inovador nas aulas de Língua Portuguesa do EJA; é simples, mas conecta mundos, trazendo novas experiências no ato de aprender de jovens e adultos do EJA.

Dito isso, e tratando especialmente do ensino de língua materna, passamos à reflexão sobre o processo de escolha curricular para o ensino de língua, a qual deve almejar desenvolver competências para que o aluno tenha consciência crítica e domínio das diferentes linguagens, inserido em seu contexto sociocomunicativo. Não se trata de desprestigiar os gêneros mais canônicos e consagrados nas práticas de ensino, mas incluir os novos gêneros e as novas perspectivas de multiletramentos no espaço social da escolarização.

Há muito se fala sobre a língua como produção social (GERALDI, 1984). O ensino de língua materna passa a ser visto além das questões pedagógicas tradicionais - com o ensino de gramática - e insere-se a leitura e a produção textual, instaurando um novo paradigma que se mantém até hoje, como visto na proposta da BNCC. A partir deste momento, vemos que os educadores decidem por empregar uma maior variedade de gêneros textuais nos livros didáticos, buscando uma aproximação da língua ensinada na escola com aquela presente na realidade dos alunos. Esta característica também foi relatada por Silva e Trotta (2019, p.40), que declaram:

Percebem-se acentuadas mudanças do ensino de Língua Portuguesa ocorridas nas últimas três décadas, em que o ensino gramatical deu lugar ao texto como objeto central do processo pedagógico, e a concepção de ensino de teoria da comunicação à concepção de interação.

No entanto, o assunto da multimodalidade tarda a aparecer nas propostas curriculares, que privilegiam textos escritos para descrição e análise. No manifesto do New London Group (NLG, 1996), formado por estudiosos da educação, dentre eles Courtney Cazden, Bill Cope, Norman Fairclough, Jim Gee, Mary Kalantzis, Gunther Kress, Carmen Luke, Sara Michaels e Martin Nakata, privilegia-se a utilização das diversas semioses do mundo pós-moderno, vinculado aos inúmeros aspectos culturais globalizados, a fim de se construir sentido em um mundo cada vez mais tecnológico.

O grupo defende uma concepção mais dinâmica de representação do significado e utiliza o termo "design" para caracterizar os processos de constituição do conhecimento e 
seus significados. Dentro deste modelo, o aluno é capaz de construir e reconstruir seu conhecimento a partir da consideração de sua identidade e do mundo a sua volta.

A proposta da pedagogia de multiletramentos, iniciada em Nova Londres em 1996 e defendida aqui principalmente por ROJO (op.cit.) admite que a escola deve abrir espaço para o plurilinguismo, isto é, para a grande diversidade cultural e semiótica na construção dos textos utilizados para a comunicação. Tais textos são vistos como colaborativos, saindo da esfera de produção individual, ao mesmo tempo que são híbridos, fronteiriços em relação a várias linguagens (ROJO; MOURA, 2012).

Na próxima seção, veremos como a BNCC trata da questão dos multiletramentos no ensino.

\subsubsection{Adequação do ensino dos multiletramentos às propostas da BNCC}

Hoje, a tecnologia é vista como uma ferramenta de geração de novos conhecimentos, não limitando o aprendizado ao papel e à oralidade, como se trabalhava antes da mudança de paradigma inaugurada na década de 1980. A proposição de práticas de leitura e escrita mais condizentes com a nova realidade nos leva a perceber práticas mais situadas, que conduzem os alunos a uma forma de aprendizagem cada vez mais crítica e autônoma. Para tal, é preciso saber gerenciar os recursos que as tecnologias oferecem.

Neste âmbito, tendo em vista que aqui analisamos a proposta de ensino de Língua Portuguesa com o uso de diferentes gêneros, a BNCC apresenta a inserção de gêneros multimodais e uma maior consideração sobre a cultura digital do que a vista nos antigos PCNs - Parâmetros Curriculares Nacionais (BRASIL, 1998). Mesmo assim, é importante darmos valor às proposições deste último documento: os PCNs trouxeram um grande avanço sobre a questão do uso de textos de gêneros variados, porém a perspectiva da comunicação digital ainda não tinha ganhado tanta relevância no contexto educacional da sociedade da década de 1990.

No entanto, ao pensarmos sobre a BNCC, por ser um documento aberto à adequação de cada secretaria de Educação, o alcance dos textos digitais pode ser restrito, a depender dos materiais selecionados nas escolhas locais de cada município. Também não podemos nos esquecer da diversidade socioeconômica de nosso país, que revela uma saliente desigualdade em relação ao acesso aos bens de consumo e, consequentemente, ao contato com os aparelhos de suporte para os textos digitais, tais como computadores, tablets e smartphones.

A BNCC sinaliza para o uso de textos em sala de aula mais relacionados às práticas digitais, sem abrir mão dos textos impressos. Apesar de não possuir uma concepção de gênero muito clara - ora pendendo para sua descrição, ora com viés estruturalista preconiza a produção de textos mais diversificados, com um olhar mais atento para a cultura digital. O texto considera o aluno como crítico e autor dos diferentes usos da linguagem, uma vez que os suportes midiáticos podem suprimir as relações de propriedade, tornando-se colaborativos.

Quanto ao componente de Língua Portuguesa, a BNCC discorre sobre o ensino de um conhecimento mais complexo das linguagens, a fim de que os jovens possam se desenvolver nos campos: vida pessoal; vida pública; artístico-literário; práticas, estudos e pesquisa e jornalístico-midiático. Desta forma, vemos uma perspectiva de uso das linguagens de forma coletiva e inserida em comunidade. Ao relacionar a multiplicidade de textos e tecnologias, classifica a leitura e produção textual como práticas social e historicamente situadas. Com base nas experiências e vivências dos alunos na sociedade. 
Ao apresentar os conteúdos para ensino de Língua Portuguesa para a Educação Básica, a BNCC propõe a "análise de elementos discursivos, composicionais e formais dos enunciados nas diferentes semioses" (BRASIL, 2018, p. 486). O documento trata de diversas competências em campos que incluem o estudo de gêneros multimodais (que implicam multiletramentos). Dentre elas, cabe dotar os alunos de competências que o permitam utilizar essas linguagens com senso de autonomia, colaboração e autoria; reconhecer a língua como fenômeno variável, que pode ser utilizada de diferentes modos a depender de seus objetivos sociocomunicativos; e realizar práticas discursivas no mundo digital, de modo que se possa estudar linguagens em situações reais de uso.

Podemos verificar esta perspectiva no seguinte trecho, que dispõe sobre o aprendizado de ferramentas tecnológicas na escola:

(...) propostas de trabalho que potencializem aos estudantes o acesso a saberes sobre o mundo digital e a[s] práticas da cultura digital devem também ser priorizadas, já que, direta ou indiretamente, impactam seu dia a dia nos vários campos de atuação social e despertam seu interesse e sua identificação com as TDIC. Sua utilização na escola não só possibilita maior apropriação técnica e crítica desses recursos, como também é determinante para uma aprendizagem significativa e autônoma pelos estudantes. (BRASIL, 2018, p. 487)

Para que isso aconteça, a BNCC propõe que sejam realizados trabalhos interdisciplinares e que os currículos, por fim definidos pelos Estados e Municípios, selecionem aspectos da cultura relevantes para a formação dos alunos, de forma progressiva, a partir dos objetivos listados para cada ano da Educação Básica. Com essas diretrizes, entendemos que a responsabilidade do professor vai exigir conhecimentos além do conteúdo de sua disciplina. É preciso conhecer as novas ferramentas de comunicação e incorporá-las, para adaptá-las a sua prática pedagógica.

Sendo assim, a leitura e a produção de textos multimodais podem ser utilizadas pelo professor na construção de projetos pedagógicos, a fim de conduzir os alunos a uma forma de aprendizagem cada vez mais autônoma. Para tal, é preciso saber gerenciar os recursos que as tecnologias oferecem, visto que as práticas discursivas estão cada vez mais presentes no mundo on-line. O professor assume um papel de facilitador da aprendizagem, levando o aluno à construção e entendimento dos multiletramentos em textos multimodais, o que o torna sujeito ativo do uso e do conhecimento da língua em situações complexas da vida contemporânea.

\section{CONSIDERAÇÕES FINAIS}

Neste trabalho, buscamos investigar as considerações da BNCC quanto ao ensino de língua portuguesa na perspectiva dos multiletramentos. Dentro das limitações deste artigo, que se propôs a uma avaliação restrita ao levantamento bibliográfico sugerido, discutimos o texto do documento oficial do governo e sua relação com a Pedagogia de multiletramentos.

A partir da mudança de paradigma sobre o ensino-aprendizagem de língua, antes pautado sobre o ensino de análise linguística e, desde os anos noventas, incluindo a leitura e produção textual como base para o ensino, a escola vem buscando contribuir para 0 letramento integral - ou multiletramentos - dos alunos. Os documentos oficiais sobre a educação no Brasil apresentam, de forma cada vez mais relevante, a importância da inclusão dos diversos gêneros textuais produzidos na atualidade, através do engajamento discursivo e do desenvolvimento de consciência crítica sobre seu próprio aprendizado, alcançados com o apoio do professor, que passa de transmissor do conhecimento a facilitador da aprendizagem significativa. 
A responsabilidade do professor ganha outros sentidos, pois exige do educador conhecimentos além do conteúdo de sua disciplina. É preciso conhecer as novas ferramentas de comunicação e incorporá-las, para adaptá-las a sua prática pedagógica. Deste modo, poderá atuar de forma mais efetiva no ensino de língua e linguagens, atendendo às demandas sociais e comunicativas globais. Não há mais como ignorar o uso dessas inovações tecnológicas e sua influência no ensino, e é papel da escola promover um espaço para que seus alunos possam se posicionar frente ao dinamismo do mundo contemporâneo.

Desta forma, ainda que vejamos lacunas a serem reparadas no documento publicado pelo Ministério da Educação do Brasil, percebemos um diálogo entre a abordagem da pedagogia de multiletramentos e as proposições feitas na BNCC, que sugere o uso de textos multimodais cada vez mais presentes com a expansão das TDIC. Este posicionamento vai ao encontro das necessidades contemporâneas de ensino, integrando o aprendizado de Língua Portuguesa às vivências em sociedade trazidas pelos estudantes.

\section{REFERÊNCIAS}

ANECLETO, U.; OLIVEIRA, M. S. Tecnologias digitais, pedagogia dos multiletramentos e formação de professor: caminhos da pesquisa colaborativa. In: FERRAZ, O. Educação, (multi)letramentos e tecnologias: tecendo redes de conhecimento sobre letramentos, cultura digital, ensino e aprendizagem na cibercultura. Salvador. EDUFBA. 2019.

BAKHTIN, M. Gêneros do discurso. In: Estética da criação verbal. São Paulo: Martins Fontes, 1992.

BRASIL. MEC. Base Nacional Comum Curricular: educação é a base. Brasília: MEC: 2018. Disponível em:

http://basenacionalcomum.mec.gov.br/wpcontent/uploads/2018/12/BNCC 19dez2018 site .pdf. Acesso em: 01 abr. 2021.

BRASIL. MEC. Parâmetros Curriculares Nacionais: terceiro e quarto ciclos: língua portuguesa. Brasília: MEC SEF, 1998.

GERALDI, J. W. (Org.) O texto na sala de aula: leitura e produção. 2. ed. Cascavel: ASSOESTE, 1985.

LEVY, P. Cibercultura. Rio de Janeiro: Editora 34, 1999.

MARCUSCHI, L. A. Gêneros textuais: definição e funcionalidade. São Paulo. 2002. In: DIONÍSIO, Ângela Paiva; MACHADO, Anna Rachel; BEZERRA, Maria Auxiliadora (org.). Gêneros textuais \& ensino. Rio de Janeiro: Lucerna, 2002.

MENDES GONTIJO, C. M. Base Nacional Comum Curricular (BNCC): comentários críticos. Revista Brasileira de Alfabetização, 1(2). 2015. Disponível em: https://doi.org/10.47249/rba.2015.v1.68. Acesso em: 10 abr. 2021.

MEURER, J. L.; MOTTA-ROTH, Desirée. (orgs.). Gêneros textuais e práticas discursivas: subsídios para o ensino de linguagem. Bauru: Edusc, 2002 
ROJO, R. Linguagens, códigos e suas tecnologias. In: BRASIL. Ministério da Educação. Secretaria de Educação Básica. Departamento de Políticas do Ensino Médio. Orientações curriculares do ensino médio. Brasília, 2004.

ROJO, R.; MOURA, E. (orgs.). Multiletramentos na escola. São Paulo: Parábola Editorial, 2012.

SILVA, C.T.C.; TROTTA, L. Educação de jovens e adultos e língua portuguesa: um estudo da inovação possível a partir da percepção de alunos e professores de outras disciplinas. RECITE - Revista Carioca de Ciência, Tecnologia e Educação. Rio de Janeiro: v. 4, n. 1, jul./dez., 2019. DOI: https://doi.org/10.17648/2596-058X-recite-v4n1-4 Acesso em: 10 abr. 2021.

SWALES, J. M. Genre analysis: English in academic and research settings. Cambridge: CUP, 1990.

THE NEW London Group. A pedagogy of multiliteracies: designing social futures. Harvard Educational Review, Cambridge.66(1), 60-92, 1996. 